\title{
Cycles and shifts: 1,300 years of multi-decadal temperature variability in the Gulf of Alaska
}

\author{
Rob Wilson • Greg Wiles · Rosanne D'Arrigo • \\ Chris Zweck
}

Received: 27 April 2006/ Accepted: 7 September 2006/Published online: 17 October 2006

(C) Springer-Verlag 2006

\begin{abstract}
The Gulf of Alaska (GOA) is highly sensitive to shifts in North Pacific climate variability. Here we present an extended tree-ring record of JanuarySeptember GOA coastal surface air temperatures using tree-ring width data from coniferous trees growing in the mountain ranges along the GOA. The reconstruction (1514-1999), based on living trees, explains $44 \%$ of the temperature variance, although, as the number of chronologies decreases back in time, this value decreases to, and remains around $\sim 30 \%$ before 1840. Verification of the calibrated models is, however, robust. Utilizing sub-fossil wood, we extend the GOA reconstruction back to the early eighth century. The GOA reconstruction correlates significantly (95\% CL) with both the Pacific Decadal Oscillation Index (0.53) and North Pacific Index $(-0.42)$ and therefore likely yields important information on past climate variability in the North Pacific region. Intervention analysis on the GOA reconstruction identifies the known twentieth century climate shifts around the 1940s and 1970s, al-
\end{abstract}

R. Wilson $(\bowtie)$

School of GeoSciences, Grant Institute,

Edinburgh University, West Mains Road,

Edinburgh EH9 3JW, Scotland, UK

e-mail: rob.wilson@ed.ac.uk

G. Wiles

The College of Wooster, Wooster, OH, USA

R. Wilson · R. D'Arrigo

Tree-Ring Laboratory, Lamont-Doherty Earth

Observatory, Columbia University, Palisades, NY, USA

C. Zweck

Department of Hydrology and Water Resources,

University of Arizona, Tucson, AZ, USA though the mid-1920s shift is only weakly expressed. In the context of the full 1,300 years record, the well studied 1976 shift is not unique. Multi-taper method spectral analysis shows that the spectral properties of the living and sub-fossil data are similar, with both records showing significant (95\% CL) spectral peaks at -9-11, 13-14 and 18-19 years. Singular spectrum analysis identifies (in order of importance) significant oscillatory modes at 18.7, 50.4, 38.0, 91.8, 24.4, 15.3 and 14.1 years. The amplitude of these modes varies through time. It has been suggested (Minobe in Geophys Res Lett $26: 855-858,1999)$ that the regime shifts during the twentieth century can be explained by the interaction between pentadecadal (50.4 years) and bidecadal (18.7 years) oscillatory modes. Removal of these two modes of variance from our GOA time series does indeed remove the twentieth century shifts, but many are still identified prior to the twentieth century. Our analysis suggests that climate variability of the GOA is very complex, and that much more work is required to understand the underlying oscillatory behavior that is observed in instrumental and proxy records from the North Pacific region.

\section{Introduction}

During the twentieth century in the North Pacific, there have been at least three documented shifts ( 1925, 1945 and 1976) in the ocean-atmospheric climate regime (Mantua et al. 1997; Labeyrie et al. 2003) that have significantly impacted commercial fish populations (Mantua and Hare 2002; Chavez et al. 
2003; Beamish et al. 2004) and other ecosystems (Ebbesmeyer et al. 1991). It is not yet known whether such shifts in regime result from external forcing (e.g., solar and lunar effects), internal forcing of the North Pacific climate system (e.g., Nakamura et al. 1997) or originate in the tropics (Trenberth and Hurrell 1994; Minobe 1997; Zhang et al. 1998; Garreaud and Battisti 1999; Evans et al. 2001; Deser et al. 2004). In fact, it is not even known whether such shifts are cyclical in nature, or are instead related to chaotic/random changes in the ocean-atmospheric system. Instrumental records are not long enough to place these twentieth century changes in a longer-term context and therefore a true understanding of the temporal and spatial modes of these synoptic features is not possible from these data alone. However, annually resolved proxy archives like tree-rings and corals have been successfully used to reconstruct synoptic indices of Pacific Decadal Variability (Linsley et al. 2000; Biondi et al. 2001; D'Arrigo et al. 2001; Gedalof and Smith 2001; Gedalof et al. 2002; D'Arrigo et al. 2005; D'Arrigo and Wilson 2006). From the growing database of these proxies, it may soon be possible to make specific inferences about past decadal variability and its forcing mechanisms.

Herein, we detail the development of a new treering based reconstruction of coastal land surface air temperatures for the Gulf of Alaska (GOA). GOA temperatures are largely dominated by the Aleutian Low, a prominent feature of North Pacific decadal variability, during the winter and spring months (Wilson and Overland 1987; Trenberth and Hurrell 1994). GOA temperatures (winter and spring) therefore correlate strongly to fluctuations of the Pacific Decadal Oscillation (PDO), an important large-scale climate index defined as the dominant mode of North Pacific SSTs (Mantua et al. 1997), and to the North Pacific Index (NPI), an indicator of the intensity of the Aleutian Low pressure cell (Trenberth and Hurrell 1994). Thus, the reconstruction described herein provides important information on past fluctuations in GOA temperatures that are related to these indices and to North Pacific climate variability. Previous reconstructions of GOA land (Wiles et al. 1998) and sea surface temperatures (SST; D'Arrigo et al. 1999) although well calibrated and verified, were restricted in length due to the relative shortness and paucity of treering chronologies then available for the region. In this study, we not only utilize a substantially larger treering data-set of living chronologies, but also extend this living data-set using snag (i.e., preserved standing woody material) and buried sub-fossil woody material. As will be shown, this extended record provides longterm multi-decadal information on GOA climate var- iability over the past 1,300 years, complementing related efforts to develop paleoclimatic time series for coastal and other regions of Alaska on millennial time scales (Barclay et al. 1999; Hu et al. 2001; Finney et al. 2002; Wiles et al. in preparation).

\section{Data}

\subsection{Tree-ring data}

Over the last two decades tree-ring samples have been collected from many sites along the coastal ranges bordering the GOA. For this study, we selected from the region 31 ring-width data-sets, that came up to at least 1986, from the international tree-ring data-bank (http://www.ncdc.noaa.gov/paleo/treering.html) as well as newly sampled data-sets for further investigation (Fig. 1; Table 1). Most of the chronologies are derived from either mountain hemlock [Tsuga mertensiana (Bong.) Carr.], Sitka spruce [Picea sitchensis (Bong.) Carr.] or white spruce [Picea glauca (Moench) Voss]. There is also one yellow cedar [Chamaecyparis nootkatensis (D. Don) Spach] chronology, from Basin Bushwack (Table 1). In the GOA region, the treeline is spatially highly variable and ranges from as high as $800 \mathrm{~m}$ in the southeast to about $400 \mathrm{~m}$ in the western Kenai Peninsula. Most of the sites were sampled at or close to their respective local treeline.

Crossdating of the ring-width samples was verified using the computer program COFECHA (GrissinoMayer et al. 1997) and poorly dated series were discarded. To remove non-climatic biological age-related trends (Fritts 1976), the individual raw ring-width series were detrended using negative exponential functions or regression lines of negative/zero slope (Cook and Kairiukstis 1990). For 12 of the chronologies (DM, WP, RG, EX, LL, MR, NK, TM, MW, AP, MT and KI), the Cook and Peters (1997) power transform was used to reduce end effect inflation of resultant indices in some select series. It should be noted, however, that the use or none use of the power transform makes little difference to the final reconstruction. The variance of the chronologies was stabilized using the method of Osborn et al. (1997). Cook et al. (1995) state that using 'traditional' individual series detrending methods, as done in this study, the lowest frequency of climate information that can be realistically recovered is $3 / n$ cycles per year (where $n=$ the mean sample length). Therefore, with a mean (sites equally weighted) sample length of 260 years (Table 1), such individual series detrending will result in chronologies that can only represent variability at centennial or higher-frequency 


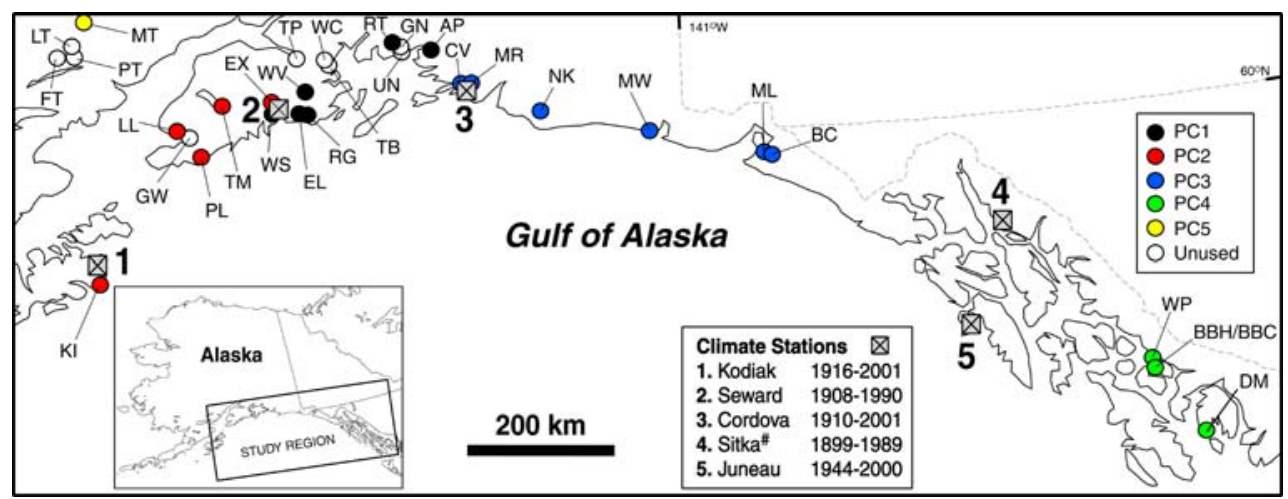

Fig. 1 Location map of tree-ring sites and climate stations used in this study (see Table 1 for more information on the tree-ring sites). Coloured circles denote which principal component (PC) each tree-ring site is most strongly loaded upon in the most replicated nest of the GOA reconstruction. The empty circles indicate those chronologies that did not pass the screening against GOA temperatures. Missing monthly values identified in each of the climate stations are; Kodiak (1917/18, 1941, 1946/47,
1979), Seward (1911, 1915, 1921, 1925-29, 1933, 1938, 1979), Cordova (1911, 1914-1918, 1942/43, 1994, 1996, 1999), Juneau (1985) and Sitka (1908-1910, 1915, 1926, 1932, 1942, 1959, 1978). \# = More data exist for Sitka that are not included in the GHCN data archive (Phil Jones, personal communication). These extra data, covering the period 1832-1887, with missing monthly values in the years $1832,1846,1847,1855,1877-1881$ and 1887 , were used for extra verification in the nineteenth century time scales. In a companion study (Wiles et al. in preparation), a subset of these data, along with data from snag and sub-fossil wood (see later) are processed using the Regional Curve Standardization (RCS) procedure (Mitchell 1967; Briffa et al. 1992; Esper et al. 2003) to capture secular scale information at wavelengths greater than a century. In this study, however, we focus on the multi-decadal information in the chronologies.

The signal strength of the chronologies was assessed using the Expressed Population Signal (EPS) statistic (Wigley et al. 1984) via a moving window analysis. We utilized the commonly applied 0.85 threshold to denote reasonable signal strength. The common period of all the chronologies with an acceptable signal strength is 1855-1986 (Table 1, note: the EPS value for the GW chronology was low $(\sim 0.6)$ in the twentieth century, possibly reflecting the influence and recovery from a severe ice storm in the 1880s). The mean inter-chronology correlation of all 31 chronologies over the 1855-1986 period is 0.31 [standard deviation $(\mathrm{STDV})=0.25]$, highlighting a reasonably high degree of variability between the chronologies. The highest between chronology correlation is 0.85 (EL vs RG) while the lowest is -0.34 (MT vs GN). This large range in inter-chronology correlations is not surprising given the large spatial coverage of the study region and different ecologies/elevations/species of the sites (Fig. 1). For this reason, therefore, the chronologies were screened to identify those with a significant regionalscale climate signal and a principal component (PC) regression (PCR, Cook et al. 1999) approach was utilized to develop the reconstruction so that the domi- nant modes of variance could be extracted from this large data-set.

\subsection{Climate data}

Monthly maximum and minimum temperature data were compiled from five coastal stations (Kodiak, Seward, Cordova, Sitka and Juneau) around the GOA (see Fig. 1 for length of each record). These station data were obtained from the Global Historical Climate Network (GHCN) and have been corrected for inhomogeneities (Peterson and Vose 1997). Using techniques outlined in Jones and Hulme (1996), the data were averaged to formulate regional monthly series of both parameters, respectively. This regionalisation of the climate data enabled the 'filling in' of missing monthly values that existed in many of the individual records (see caption of Fig. 1), helped optimize the common signal and maximized the final length (18992001) of the potential predictand data. Comparative analysis identified no significant difference between the monthly time series of both maximum and minimum temperatures and so these data were averaged together and further analysis utilized mean temperatures only. Mean temperature data for Sitka (1832-1887), that are not included in the GHCN archive, were also obtained (Phil Jones personal communication) allowing independent extra verification of the GOA reconstruction outside of the screening/calibration period.

The spatial coherence of the common signal between these five stations is likely not homogenous (i.e., there are slight differences from west to east), but due to the low number of station records, it is not possible 


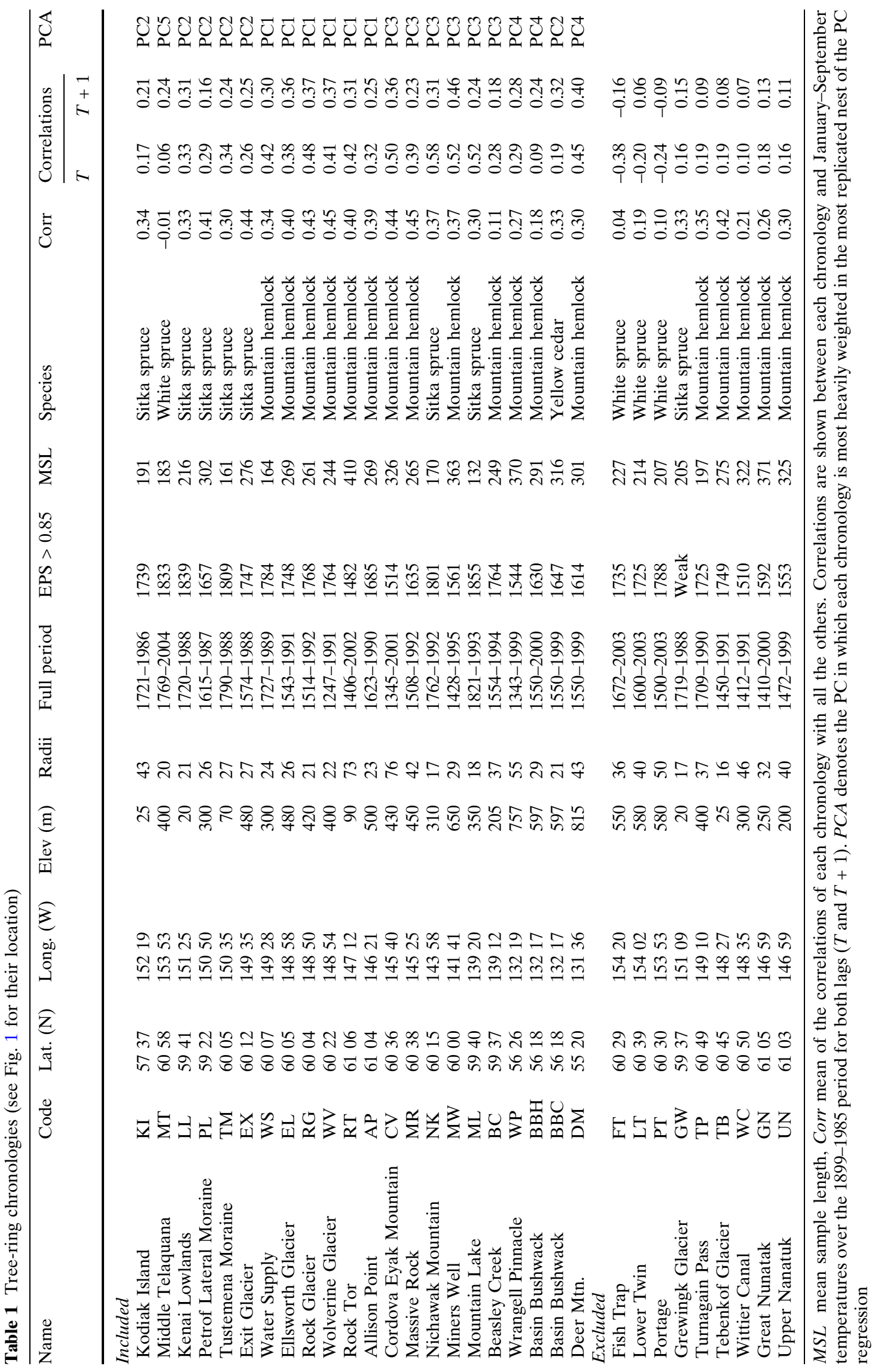


to empirically identify any spatial changes in signal. The mean inter-series correlation (analysis made over the maximum period of overlap between each bivariate pair) for January-September mean temperatures (the season of the reconstruction-see later) is 0.68 $(\mathrm{STDV}=0.14)$. The lowest correlation is found between Seward and Cordova $(r=0.48, n=64)$, which are relatively close to each other (Fig. 1). The eastern stations, Juneau and Sitka, which are spatially closest (inter-series correlation $=0.93, n=43$ ), correlate with the westernmost station, Kodiak, at 0.67 and 0.61 ( $n=53$ and 63), respectively. All the inter-series correlations are significant at the $99.9 \%$ confidence limit or above. As the five station records correlate reasonably well with each other, we feel that by combining them, a valid large-scale predictand temperature series can be developed that is representative of the GOA region as a whole.

\section{Calibration and verification of GOA January-September temperatures}

Correlation analysis and PCR calibration trials between monthly temperature series and the individual chronologies identified the optimum season for reconstruction as January-September. Having identified this optimum season, the final reconstruction was developed using only those chronologies that correlated (1899-1985, the common period of the tree-ring and instrumental data) with this season at the $95 \%$ confidence limit at either lags $T$ and/or $T+1$ - the latter taking into account the effect of previous year's climate upon growth (Fritts 1976). Table 1 lists the correlations of each of the chronologies with JanuarySeptember GOA mean temperatures for both lags, and highlights those series that were utilized in the development of the reconstruction. Nine chronologies were excluded from further analysis, as they showed no significant correlation with this season. Of these nine chronologies, FT, LT, PT, GW, WC and TB are located at more 'interior' sites around the extreme western end of Prince William Sound and are likely protected from the influence of the North Pacific resulting in drier site conditions. The two chronologies from Columbia Bay (GN and UN) are located at sites that were almost surrounded by ice until $\sim 20$ years ago and therefore their growth patterns may reflect the influence of these major ice masses surrounding them.

A rotated (varimax) PC analysis (Richman 1986) using the remaining 22 chronologies identified five principal components (PCs) with an eigenvalue greater than unity. Table 1 and Fig. 1 identify those chronol- ogies which load most heavily on each PC, while the correlation response functions of each rotated $\mathrm{PC}$ with monthly temperature series are shown in Fig. 2. PC1, which explains the greatest amount of the variance $(23.5 \%)$ in the original data-set, generally shows the strongest response with temperature. Significant positive correlations are noted for previous February-May, previous September and the broad March-September season of the present year. PC2 only shows significant correlations with January of the present and previous year. PC3 shows similar strong correlations with temperature as PC1, but for different seasonal windows. Positive correlations for this PC are noted for previous March and a broad season from previous October through to July (excluding April). The empirical response of PCs 4 and 5 with temperature is with the previous year-previous January and previous $\mathrm{Au}$ gust-September for PC4 and previous January to previous May (excluding February) for PC5. It should be noted that the loadings of the individual chronologies upon each PC generally reflect the geographical locations of the sites (Fig. 1). PC1 is weighted to chronologies from the north end of Prince William Sound, while PC2 is a group from the southern Kenai Peninsula and Kodiak Island. PC3 reflects sites from eastern Prince William Sound to Yakutat Bay while PC4 loads on a cluster of sites from the southeast panhandle. The one chronology (MT) of PC5 is located in the far west of the study region on the Alaska Peninsula.

As the common period of the 22 chronologies is relatively short, a nesting procedure (e.g., Meko 1997; Cook et al. 2002) was employed to maximize the length of the reconstruction as well as to allow a robust assessment of the loss in signal fidelity-as the shorter series leave the data matrix-in the reconstruction over time. Using this method, iterative PC stepwise multiple regression-generated nested models of different lengths were generated. For each nest, lagged PCs $(T$ and $T+1)$ with an eigenvalue $>1.0$ were used as the predictor variables. A PC regression model was first developed using all available data. A second nest was based on the next common period of all series with the shortest series removed, and so on. For those nests where only one PC was identified (i.e., pre 1630 and post 1995), the individual chronologies were entered into the regression model using stepwise ( $F$-to-enter $=0.05 ; F$-to-remove $=0.10)$ multiple regressions. For each nested subset, a reconstruction was developed and separate calibration and verification statistics computed. The full calibration period (1899-1985) was split into early (1899-1942) and late (1943-1985) periods, on which calibration and verification were made. Verification was undertaken using the reduction 
Fig. 2 Correlation response function analysis (1899-1985) between the rotated principal component (PC) scores derived from the full 22 series nest and monthly temperature series. The analysis results are shown from January of the previous year to September of the current year. Significant $(95 \%$ CL) correlations are highlighted in black. The percentage values in the lower right corner denote the amount of variance each rotated PC explains of the original data matrix

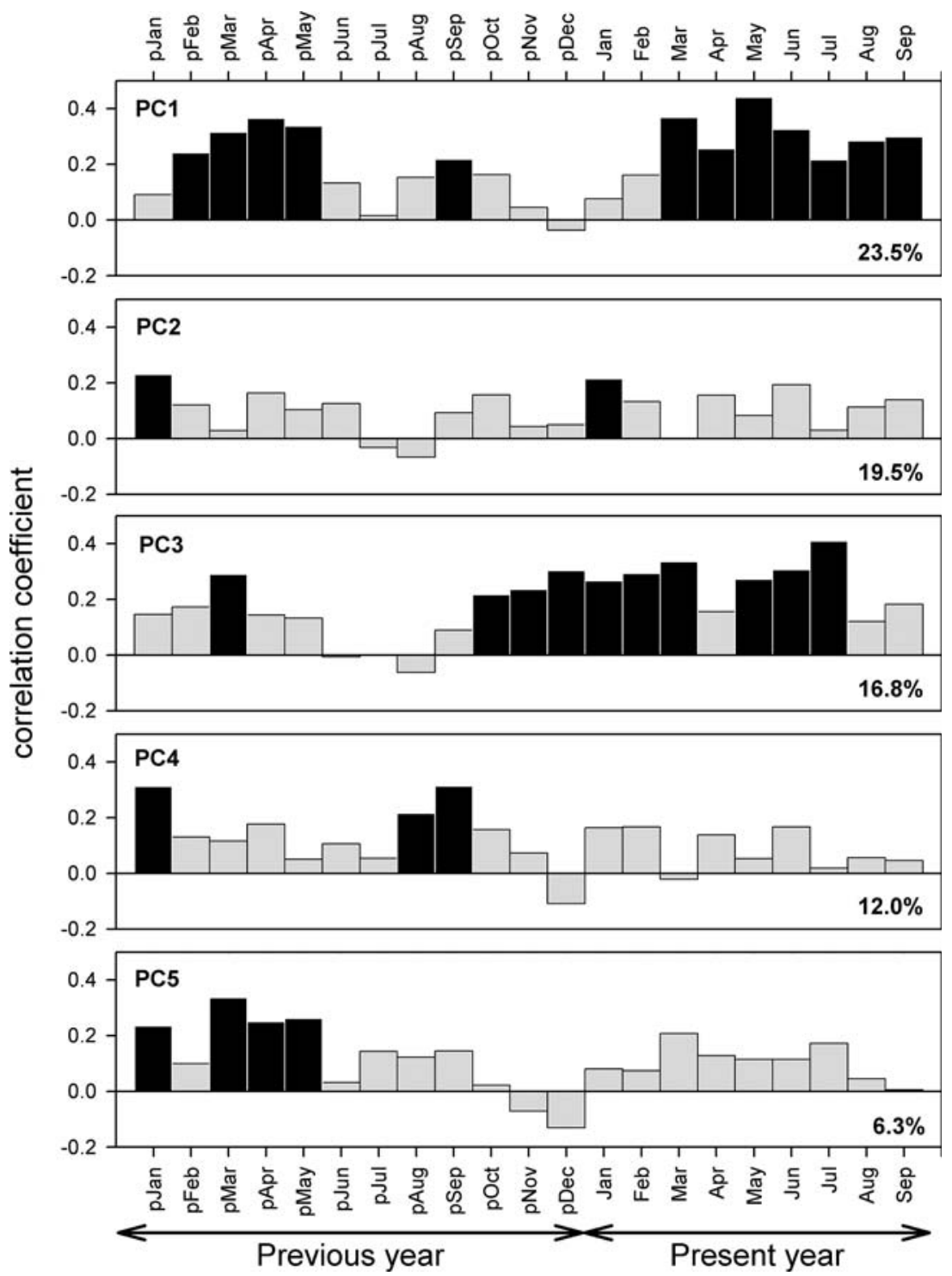

of error (RE), and the coefficient of efficiency (CE) (Cook and Kairiukstis 1990). To create the final reconstruction, the relevant segments from each full period calibrated nested model, which passed all verification tests (i.e., with significant correlation coefficients and positive RE and CE values) were spliced together. This was done after the mean and variance of each nested time series were adjusted to that of the most replicated nest to avoid artificial changes in variance due to weakening of the modeled signal.

Figure 3 presents the reconstruction with its calibration and verification results. The reconstruction was developed from 14 nested models, which passed all verification statistics. Residual analysis for each nested model (results not shown) shows that no significant autocorrelation (measured by the Durbin-Watson statistic) or linear trends were found for any of the models. Over the most replicated period (1855-1985), the reconstruction explains $44 \%$ of the temperature variance (Fig. 3a/d) - an increase compared to the previous GOA reconstructions (Wiles et al. 1998). However, prior to 1833 , there is a sharp drop in explained variance to $\sim 30 \%$ (more similar to earlier work) that remains relatively constant throughout the rest of the record (Fig. 3d).

The coherency spectrum (Fig. 3b) between the reconstructed and actual January-September temperatures shows that the modeled signal is strongest at frequencies $>\sim 13$ years although there is also some significant coherence at biennial time-scales. This former observation is important as it highlights that the reconstruction is strongest at decadal and longer timescales and may be relatively poor at capturing year-toyear variability. Despite this, however, verification is 
Fig. 3 The GOA JanuarySeptember temperature reconstruction. a Comparison of actual (GOA and Sitka temperatures) and reconstructed values, b coherency spectrum (18991985) for actual and reconstructed values, c full GOA reconstruction (smoothed with 15 year spline) with chronology replication through time. Regression equation for most replicated nest is also shown: d calibration (1899-1985) ar2 and smoothed (15 year spline) r2 statistics, e calibration (1899 1942-ar2) and verification (1943-1985, RE and CE) results, $\mathbf{f}$ As in e with calibration and verification periods reversed

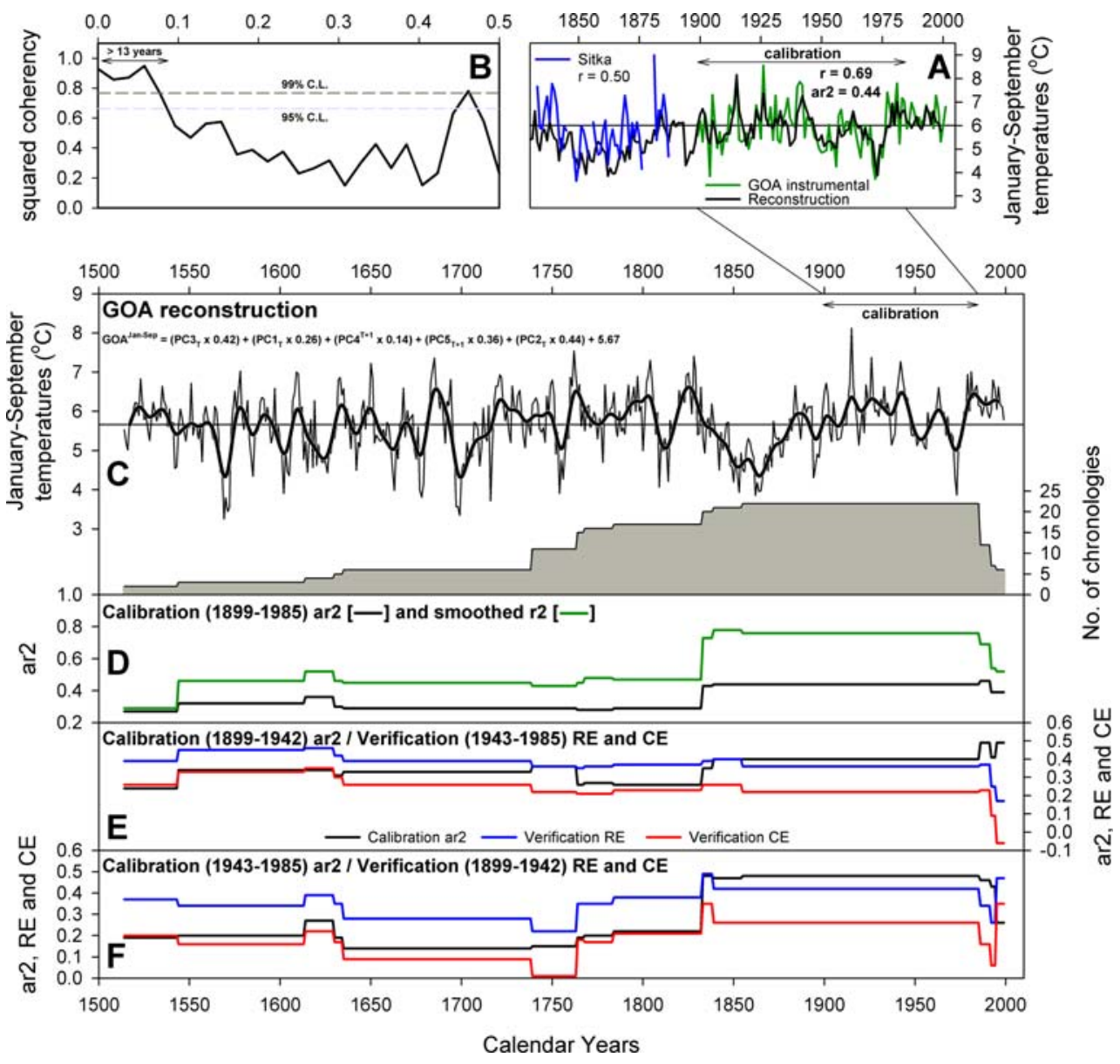

robust for the whole length of the record. The only nested model that failed verification but was allowed into the final reconstruction was for the 1995-1999 period. Although calibration on the early period shows strong coherence $\left({ }_{\mathrm{a}} r^{2}=0.49\right)$, verification over the late period failed with a $\mathrm{CE}$ value of -0.06 . However, as the $\mathrm{RE}$ is greater than zero (0.17), we included this nest as it extends the reconstruction to 1999. Comparison of the post calibration period reconstruction (Fig. 3a) shows that there is no obvious deviation between the reconstruction and actual values. The correlation between the GOA reconstruction and the early instrumental data from Sitka is 0.50 (1833-1887). However, differences in the mean values of the reconstructed $\left(4.73^{\circ} \mathrm{C}, \quad\right.$ STDV $\left.=0.90\right)$ and instrumental $\left(5.84^{\circ} \mathrm{C}\right.$, STDV $=1.07)$ series over this period result in negative $\mathrm{RE}$ and $\mathrm{CE}$ values. This failure of verification using these early instrumental data, however, may not necessarily represent a failure of the reconstruction pers se, but rather that the early instrumental data could have been 'overcorrected' in that the data of the nineteenth century have been adjusted to be internally consistent (i.e., similar mean) to the data of the twen- tieth century. As there are no neighboring stations with which to compare the early Sitka record, and these data were not included in the corrected GHCN record, we hypothesize that the problem may lie in the early instrumental data. Similar observations have also been made in Europe between dendroclimatic reconstructions and long early instrumental records (Hughes et al. 1984; Büntgen et al. 2005; Frank and Esper 2005; Wilson et al. 2005).

We should note that for the post calibration period nests (i.e., 1986-1999) the CV chronology was excluded as a potential predictor. Although we generally did not note any significant change in the response of the chronologies to climate through the twentieth century, the CV site was notable in that its index values for the last two decades decreased in a way that could not be explained by the temperature data alone. As this site correlates quite strongly with GOA temperatures (Table 1), it dominated the post 1985 nests and resulted in reconstructed values that were significantly lower than actual values. As this was the only chronology that expressed this loss in sensitivity, we feel that its exclusion from the post 1985 nests is justified. 


\section{The new GOA January-September temperature reconstruction}

Previous studies (e.g., Wiles et al. 1998; Gedalof and Smith 2001) have noted that GOA winter and spring temperatures are strongly correlated with North Pacific climate variability. We affirm this observation with spatial correlations (Fig. 4a) between the PDO index of Mantua et al. (1997) and North Pacific gridded land/ sea surface temperatures (Jones et al. 1999; Rayner et al. 2003) for the January-September season (period of analysis $=1900-1985)$. The PDO clearly correlates positively with temperatures along the GOA. Therefore, it is not surprising that a spatial correlation analysis between GOA temperatures and the land/sea gridded temperatures results in a similar spatial pattern (Fig. 4b). The GOA reconstruction also faithfully captures (albeit more weakly) this spatial pattern (at least in the twentieth century) when correlated with the land/sea temperatures (Fig. 4c).

We, however, express caution in presenting this new GOA reconstruction as a long-term index of the PDO, although it likely contains important, relevant information about this phenomenon. Rather, it is a reconstruction of GOA surface air temperatures that are strongly modulated by North Pacific ocean-atmospheric climate variability (Fig. 4b, c). This series could only be interpreted as a PDO proxy if it was known that the teleconnection between the GOA and North Pacific was time-stable-something that is currently not possible to assess on long time scales, although this issue has recently been addressed for the instrumental period (Bond et al. 2003). There are a number of reconstructions of the PDO, which have been developed from tree-ring records in recent years (Biondi et al. 2001; D'Arrigo et al. 2001; Gedalof and Smith 2001; MacDonald and Case 2005; D'Arrigo and Wilson 2006). Although these records generally agree well with each other during the twentieth century, there is relatively weak between-series coherence before this time. This may partly result from: (1) the varying spatial coverage of tree-ring data used for these PDO reconstructions; (2) the fact that the models are all calibrated during the recent period using teleconnected relationships that may not be time-stable, and/or; (3) possible modulation of local climate from El NiñoSouthern Oscillation (ENSO) and volcanic events (D'Arrigo and Wilson 2006) or other non-stationarities in the growth-climate response. However, the early lack of agreement among the PDO reconstructions may also reflect a real pattern of less coherency in the Pacific atmosphere-ocean system prior to the twentieth century (Gedalof et al. 2002; D'Arrigo et al. 2005). It should be noted, however, that a recent analysis of most of the available PDO reconstructions (Verdon and Franks 2006) indicates similar timings in regime
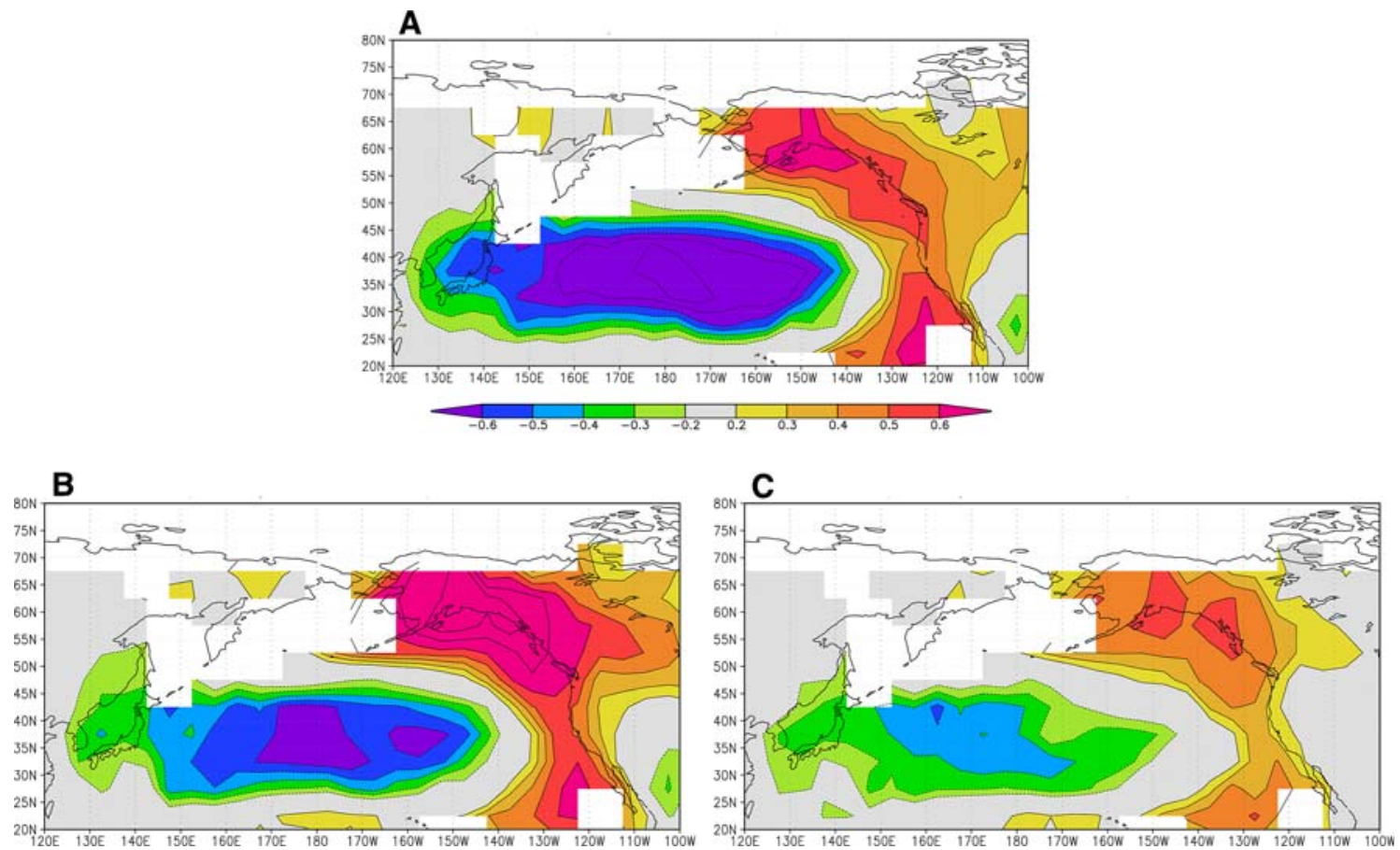

Fig. 4 Spatial correlations (1900-1985) with the CRU land/sea temperature (Jones et al. 1999; Rayner et al. 2003) data-set for the January-September season. a PDO index, b actual GOA temperatures, c reconstructed GOA temperatures 
shifts between these series over the last 400 years. This conflicting result may indicate a commonality in decadal scale variability between these series.

Figure 5 compares the new GOA reconstruction (smoothed with 15 year splines) with the two previous versions (Wiles et al. 1998) and a reconstruction of North Pacific SSTs (D'Arrigo et al. 1999) generated from GOA and Pacific NW tree-ring data. Unsurprisingly, the new reconstruction correlates significantly with these proxies, as there is a common data overlap. The greatest difference with the original March-September proxy occurs at the end of the nineteenth century, when the new reconstruction shows higher temperatures. However, due to the more comprehensive data-set used in the new reconstruction and the superior calibration/verification statistics for this period, we consider the new results to be more robust than the previous versions. This observation is partly confirmed by comparison with the early instrumental Sitka temperature data (1833-1887) with the new GOA reconstruction correlating higher $(0.50)$ than the other older reconstructions $(0.38,0.32$ and 0.46 , respectively). Over the seventeenth and eighteenth centuries, similar decadal variability is observed between the new reconstruction and the original March-May reconstruction, although the latter series appears to capture more low frequency information. In fact, the new GOA reconstruction generally shows little centennial scale variability, and much of the variability is weighted towards multi-decadal and higher frequencies. Periods of most intense reconstructed cold conditions were around $\sim 1560-1570, \sim 1690-1710$ and $\sim 1830-1870$ while periods of prolonged warmer conditions are noted from $\sim 1720$ to 1820 and the twentieth century. Wiles et al. (in preparation) show that additional lower frequency (centennial to millennial) information can be gleaned from these data when appropriately processed using the RCS method.

\section{Climate regime shifts in GOA temperatures}

As stated earlier, Pacific Decadal Variability is dominated in the twentieth century by three regime shifts: $\sim 1925, \sim 1945$ and 1976 (Mantua et al. 1997). Figure 6 compares the GOA reconstruction and instrumental data with a variety of climate indices that are commonly used to portray decadal variability in the North Pacific. The Rodionov (2004) method has been utilized to identify significant shifts in these time series. We use this method instead of the more common Box and Tiao (1975) intervention analysis-applied by Mantua et al. (1997); Gedalof and Smith (2001); D'Arrigo et al. (2005)-because we are interested in identifying shifts caused by oscillatory behavior in the climate system (see later). The AR modeling of the
Fig. 5 Comparison of new GOA reconstruction with previous (Wiles et al. 1998; D'Arrigo et al. 1999) versions. All series were smoothed with a 15 year spline and normalised to the common period. The correlations (calculated using unfiltered versions of the data) are between each series and the new GOA reconstruction. The first value is for the full period of overlap, while the value in parentheses was calculated over the 1899-1983 period

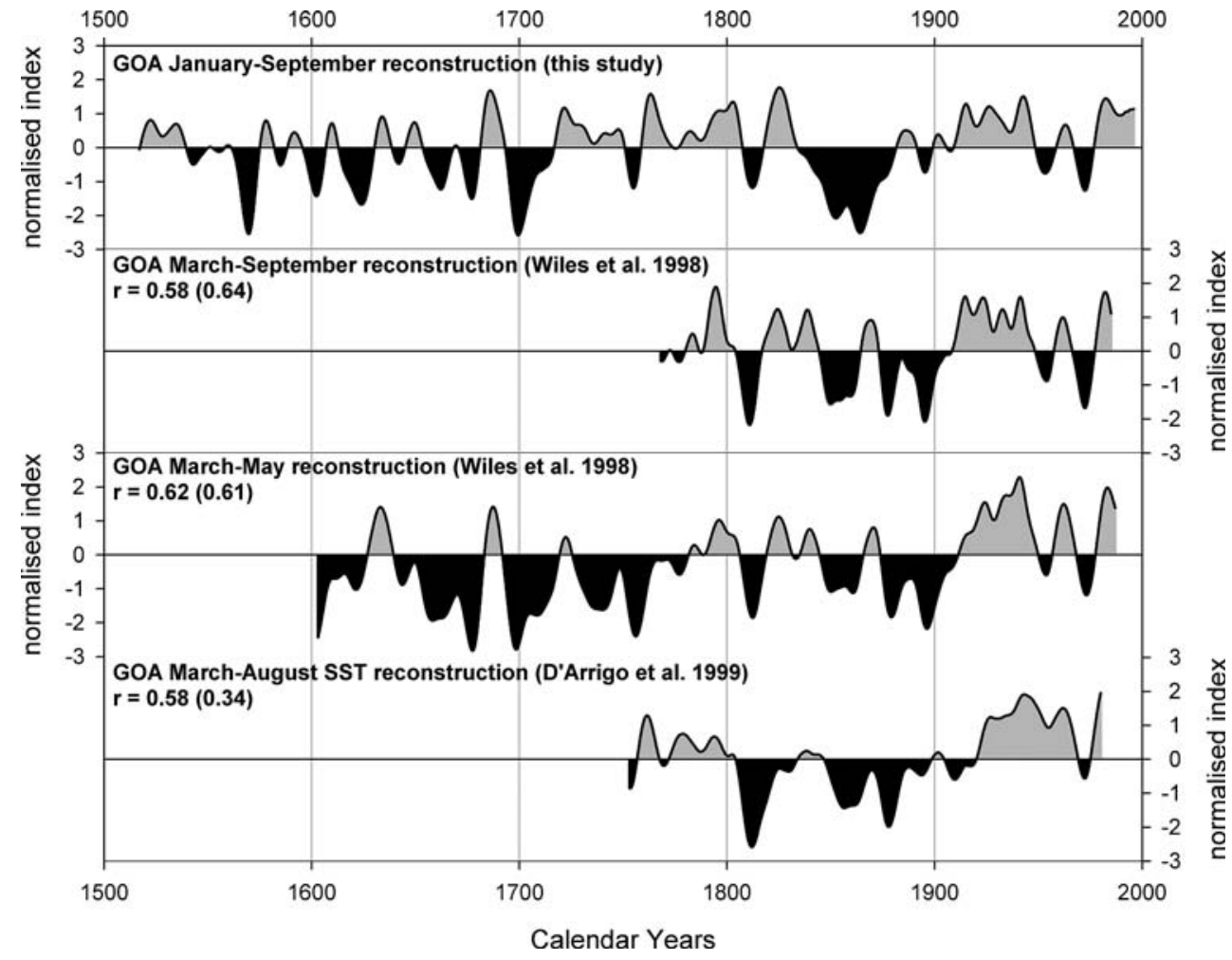


Fig. 6 Comparison of actual and reconstructed GOA temperatures with several large-scale synoptic indices (normalised to the common 1900-1994 period). The vertical lines (and dates) denote significant (95\% CL) shifts in the time series. Correlations (lower right; all significant at the $95 \%$ confidence limit) are with the reconstruction, calculated over the 1900-1985 period. The Rodionov (2004) method was used to identify the regime shifts (window length $=20$ years with a kappa value of 3). It should be noted that at the $90 \% \mathrm{CL}$, shifts are identified in the GOA reconstructed and instrumental data at 1923 and 1926, respectively

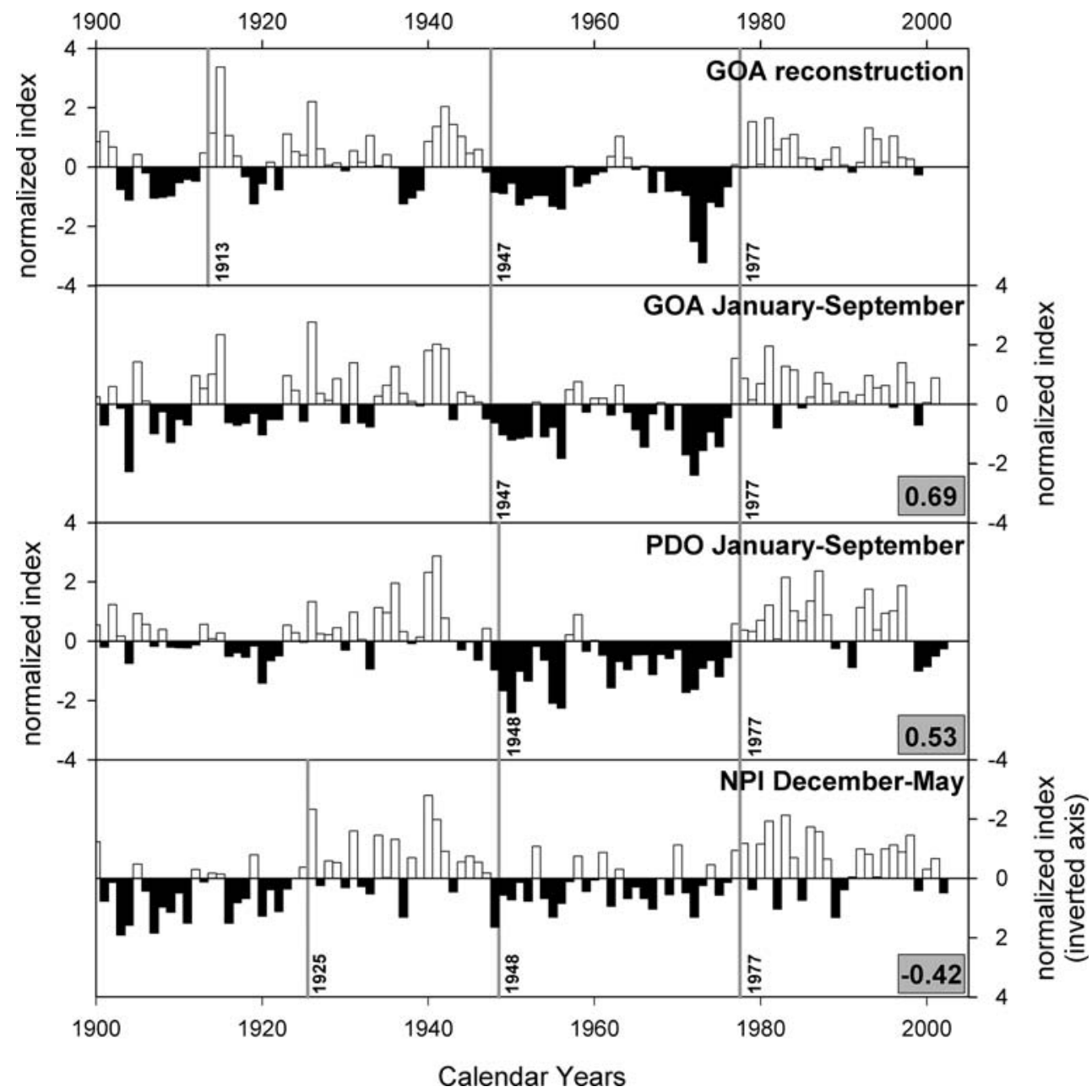

Box and Tiao (1975) method could remove these oscillatory modes.

The GOA reconstruction clearly captures the mid1940s and 1970s shifts observed in the GOA instrumental data. These shifts are also identified in the PDO (Mantua et al. 1997), and the NPI. The mid-1920s shift, which is the weakest of the documented shifts in the twentieth century in the North Pacific (Mantua et al. 1997), is not identified in either the GOA or PDO records-presumably related to the broader season (i.e., January-September vs November-March) analyzed in this study. However, at the $90 \%$ significance level, shifts are identified at 1923 and 1926 for the reconstructed and instrumental GOA records, respectively. At the $95 \% \mathrm{CL}$, however, a shift is identified at 1913 when the full length of the reconstruction is utilized.

Figure 6 indicates that the GOA reconstruction reasonably captures the regime shifts portrayed by the instrumental data. Figure $7 \mathrm{a}$ shows the full GOA reconstruction with all significant (95\% CL) shifts identified using the Rodionov (2004) method. Clearly the magnitude of the twentieth century shifts is not unique in context of the preceding 400 years, although the twentieth century is the only century period with three shifts. When compared to the published shifts identified in reconstructions of the PDO (Gedalof and Smith 2001) and NPI (D'Arrigo et al. 2005), there seems little commonality between the empirically derived regime changes. In fact, the only common shift before the twentieth century for all three reconstructions is $\sim 1696$ which possibly reflects the common response of trees to volcanic induced cooling (Briffa et al. 1998). A shift at 1840 (Fig. 7a) is also identified in the Gedalof and Smith (2001) PDO reconstruction. These differences may be related to different tree-ring data-sets used, differing processing methods of the tree-ring data and the use of different intervention analysis methods. We should note, however, that the shifts identified in the GOA reconstruction (Fig. 7a) match very closely to those identified by Verdon and Franks (2006) in their composite proxy PDO index. 
Fig. 7 Comparison of GOA reconstruction with the subfossil chronology. The subfossil data have been scaled to the reconstruction over the period of overlap (15141847). a The GOA reconstruction time series, b period of overlap with sliding 31 years correlations, c the scaled sub-fossil chronology. The vertical lines (with dates) in a and $\mathbf{c}$ show significant $(95 \% \mathrm{CL})$ regime shifts in the time series, d series replication in the sub-fossil chronology

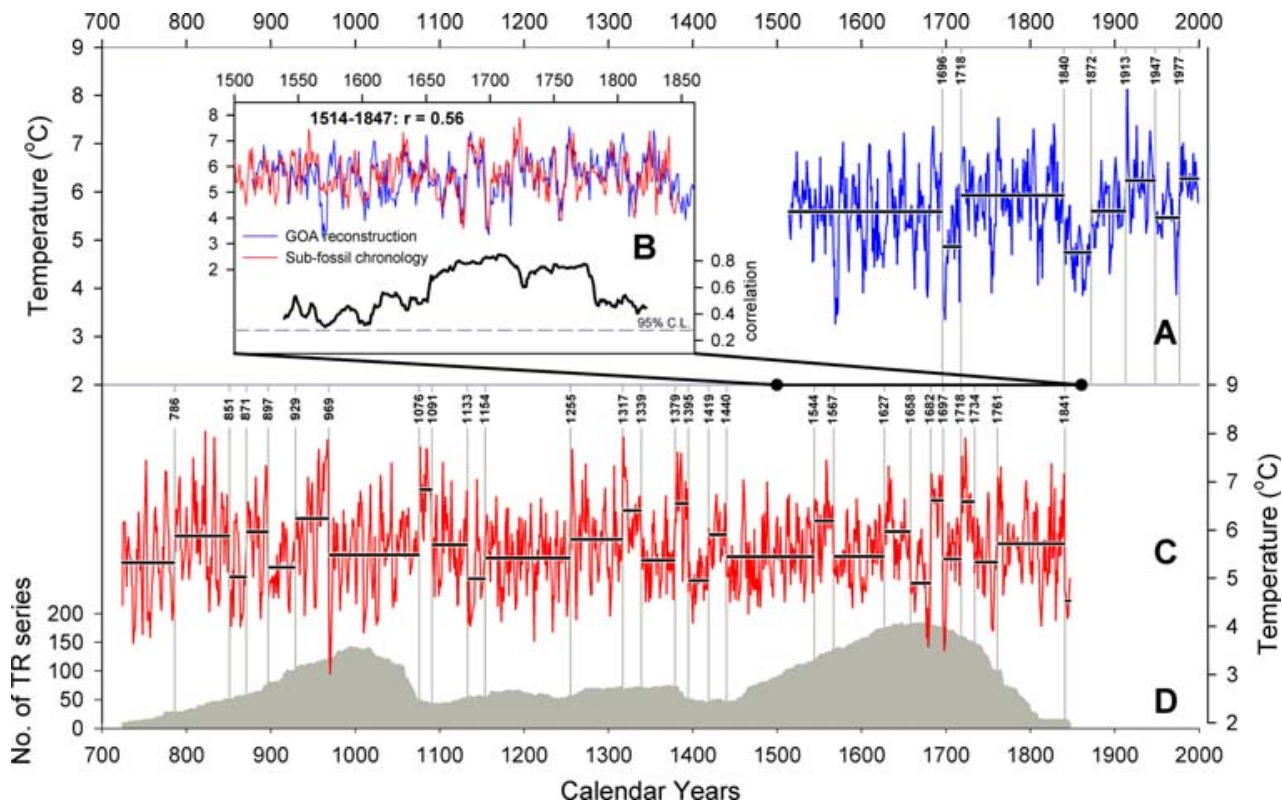

\section{Extension of GOA temperatures back to the eighth century}

A well-replicated extension of the GOA reconstruction can be made by using tree-ring measurements from snag and sub-fossil material sampled from the western end of Prince William Sound (near the TB site) and close to the living sites RT, GN and UN (Fig. 1). In total, 491 precisely dated tree-ring series, with a mean sample length of 195 years, cover the period 616-1876. These data were detrended, as one chronology, using similar methods as those used for the individual living chronologies and so, similar to the living chronologies, are likely biased to centennial or higher-frequency time scales (Cook et al. 1995). For comparison with the GOA reconstruction, the resulting sub-fossil chronology was used over the period with an EPS value $\geq 0.85$ (724-1847) and scaled (i.e., same mean and variance) to the GOA reconstruction over the common 1514-1847 periods. The two series correlate well ( $r=0.56$; Fig. 7b) over this period, although coherence is particularly strong $(r=\sim 0.7-0.8)$ over the $\sim 1650-1775$ period when replication is high in the subfossil chronology (Fig. 7d). Figure 7c plots the scaled chronology along with significant shifts identified using the Rodionov (2004) intervention analysis. Common shifts in the GOA reconstruction and sub-fossil chronology are found at $\sim 1696,1718$ and $~ 1840$. Interestingly, the sub-fossil chronology also shows common shifts with the Gedalof and Smith (2001) PDO and D'Arrigo et al. (2005) NPI reconstructions as well as the Verdon and Franks (2006) composite proxy PDO index at 1627, $1660,1680, \sim 1734$ and $\sim 1760$ that are not identified in the GOA reconstruction itself, further suggesting that the sub-fossil chronology is a valid extension to the living reconstruction.

\section{Cycles and shifts in reconstructed GOA temperatures}

A multi-taper method (MTM) spectral analysis (Mann and Lees 1996) was performed separately on the GOA reconstruction (1514-1999) and sub-fossil chronology (724-1847). Interestingly, similar spectral properties are identified at decadal and multi-decadal frequencies (Fig. 8), with both records showing significant (95\% CL) spectral peaks at $\sim 10-11,13-14$ and 18-19 years. The sub-fossil chronology also shows a significant peak at $\sim 6$ years.

Minobe (1999) hypothesized that interdecadal oscillations may be the cause of the observed regime shifts in the twentieth century. He stated that the interchange between pentadecadal ( $\sim 50$ years) and bidecadal ( 20 years) variations modulated winter and spring variability of the Aleutian Low with the pentadecadal variation providing the basic time-scale of the regime shifts and the bidecadal variability controlling the rapidity of change. Minobe (1999) tested this hypothesis using the NPI, which only encompasses the three twentieth century shifts. Our long proxy record provides an important data-set to test his ideas over a longer time period. Initially, the tree-ring data do not seem to fit with Minobe's hypothesis as there are long periods (e.g., prior to $\sim 850, \sim 970-1070, \sim 1150-1250$ and $\sim 1450-1650$ ) where few shifts are identified (Fig. 7c) 
Fig. 8 Multi-taper method spectral analysis (Mann and Lees 1996) for the GOA sub-fossil chronology (b 7131847). Number of tapers $=3$; Dashed significance line $=95 \%$ CL Significant peaks are labelled reconstruction (a 1514-1999)

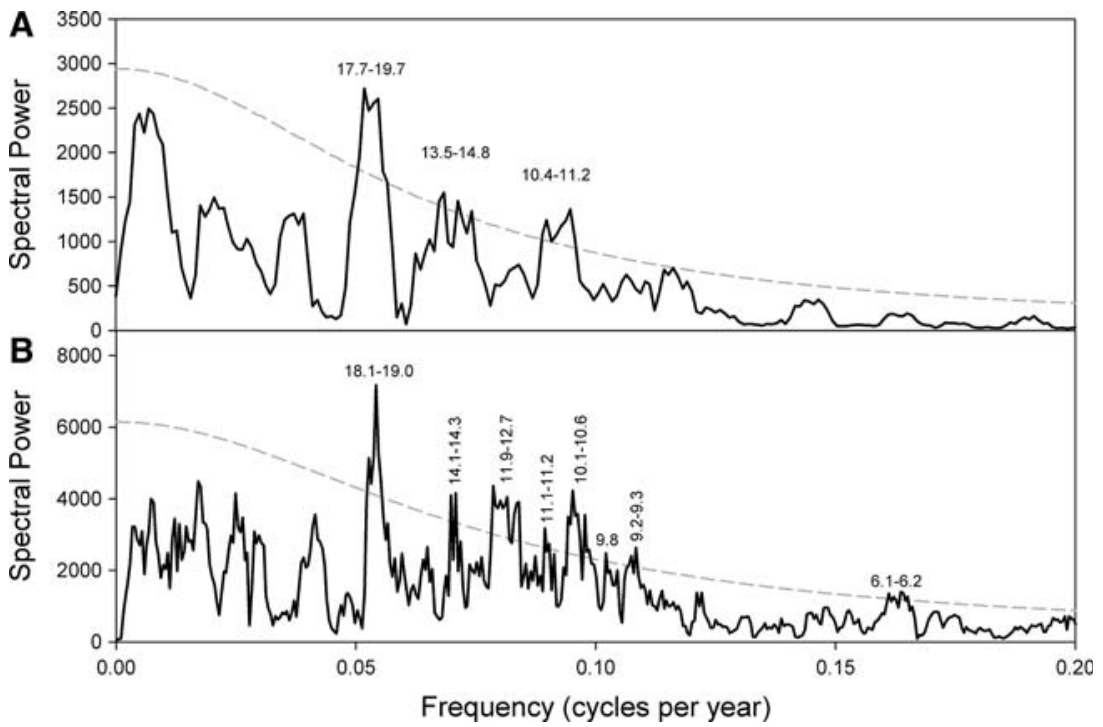

and the MTM spectral analysis (Fig. 8) does not identify a significant oscillatory mode around $\sim 50$ years, although there is a strong bidecadal mode centered around 18.5 years. However, the median time period between the identified shifts (Fig. 7) is 32 and 25 years for the GOA reconstruction and sub-fossil series, respectively. These results appear intriguingly close to the theoretical 25 years value that would be expected if indeed a 50 years cycle did dominate the temperature variability in this region.

In order to further investigate possible oscillatory modes in the GOA reconstruction, singular spectrum analysis (SSA, Vautard and Ghil 1989) was performed on the merged ${ }^{1}$ living and sub-fossil time series from 724 to 1999 (hereafter denoted as the full GOA series). Prior to analysis, as we are interested in decadal and longer time-scales, the full GOA series was low-pass filtered using a 10 years smoothing spline to remove the high frequency variability. In decreasing order with respect to how much variance of the original time series each eigenvector explains, the SSA identified oscillatory modes at 18.7, 50.4, 38.0, 91.8, 24.4, 15.3 and 14.1 years. A secular mode was also identified at frequencies $>\sim 150$ years. Although some of these modes agree well with the MTM spectral analysis (Fig. 8), the red-noise behavior in the full GOA series is clearly more complex than a few simple modes of variability.

\footnotetext{
$\overline{1 \text { The GOA }}$ and sub-fossil series (Fig. 7) were averaged over their common 1514-1847 periods. To compensate for the resultant reduction in variance from the averaging, the variance of the new mean series over the 1514-1847 was adjusted so that it was the same as the original GOA reconstruction over the same period. The variance of the pre 1514 and post 1847 periods was not adjusted.
}

Following Minobe's (1999) hypothesis, it would be expected that by re-creating the full GOA series, but excluding the two dominant 18.7 and 50.4 years modes, no rapid regime shifts would be identified in the resultant time series. Firstly, for comparison, Fig. 9a shows the full GOA series and associated regime shifts identified using the Rodionov (2004) intervention analysis method. The shifts are identical to those in Fig. 7 except for over the period of overlap (15141847) where the GOA reconstruction and sub-fossil chronology were averaged together. Using SSA, we extracted the dominant bidecadal (18.7 years, Fig. 9b) and pentadecadal (50.4 years, Fig. 9c) modes of variability and by recombining the high-pass fraction that was initially removed, reconstructed the original full GOA series without these two oscillatory modes. The correlation of this reconstructed time series with the original full GOA series is 0.88 (Fig. 9d). However, despite the absence of bidecadal and pentadecadal modes of variability, intervention analysis still identifies many shifts within the time series. In fact, more shifts are identified compared to the original time series (Fig. 9a) although the three twentieth century shifts are now absent.

The bidecadal (18.7 years, Fig. 9b) and pentadecadal (50.4 years, Fig. 9c) modes show a varying amplitude through time. When these two oscillatory modes are combined (Fig. 9e), the resultant time series does indeed express regular shifts every $\sim 25$ years for the periods $\sim 1250-1530$ and $\sim 1700$ to present. These periods roughly equate to the periods when the amplitude variance of the 50.4 years mode is greatest (Fig. 9c). However, of the 23 shifts identified in Fig. 9e, only 12 agree (i.e., roughly the same time) with the shifts identified in the full GOA series (Fig. 9a). 
Fig. 9 Intervention and singular spectrum analysis results: a the full GOA series with identified $(95 \%)$ regime shifts, b 18.7 years oscillatory mode, c 50.4 years oscillatory mode, $\mathbf{d}$ reconstructed full GOA series without the 18.7 and 50.5 years modes, e sum of the 18.7 and 50.5 years modes. The values in the lower left hand corner of each panel shows the correlation of that respective time series with the original full GOA series in panel $A$

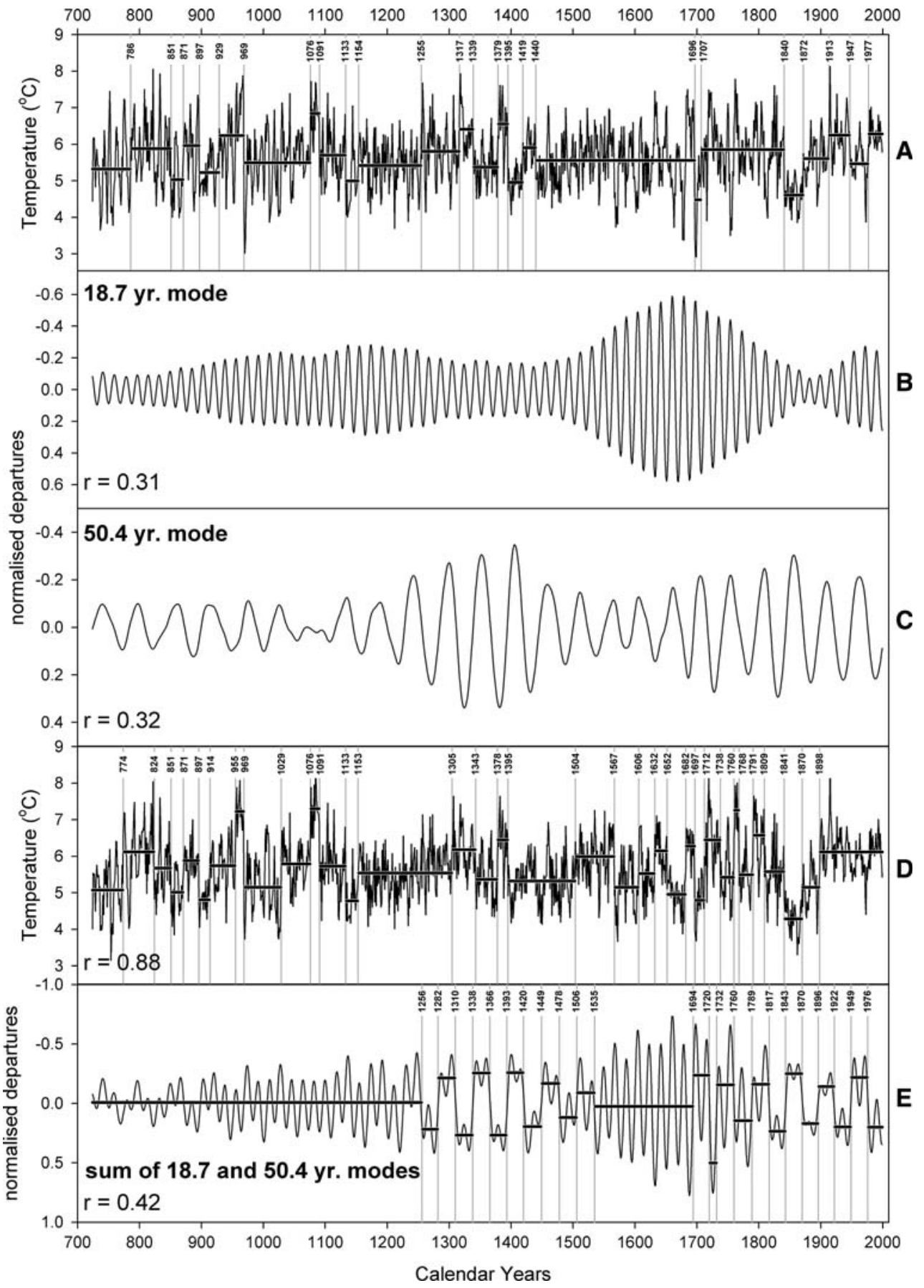

\section{Discussion and conclusions}

We have presented an updated temperature reconstruction for the GOA. The reconstruction (15141999), based on 22 ring-width chronologies from living trees, explains $44 \%$ of the temperature variance over the most replicated period, although this value decreases to $\sim 30 \%$ as the number of chronologies decreases back in time (Fig. 3). A regional composite sub-fossil chronology, which correlates reasonably strongly with the reconstruction was used to extend the living reconstruction back to the eighth century. This extended composite series displays annual to multidecadal variations in GOA surface air temperatures over the past 1,300 years and shows that the twentieth century regime shifts are not unique in the context of the previous millennium (Figs. 7, 9a).

Spectral analyses (Fig. 8) suggest that there is a degree of regulatory behavior in GOA temperatures throughout this period, at least at decadal and multi- 
decadal time-scales. Minobe (1997) identified a $\sim 50$ years (pentadecadal) mode of variation in North Pacific instrumental temperatures, which he later (Minobe 1999) hypothesized might be the underlying reason, modulated by a $\sim 20$ years (bidecadal) oscillatory mode, for the observed regime shifts in the twentieth century. Using our 1,300 years series, we tested this hypothesis using singular spectrum analysis. Two oscillatory modes were identified at 18.7 and 50.4 years, which together can explain the three shifts in the twentieth century. However, many of the identified shifts in the full GOA series prior to the twentieth century could not be explained by these two modes of variability alone (Fig. 9).

The long-term variability of GOA temperatures and the forcings upon this variability are complex and still not well understood. As well as the 18.7 and 50.4 years modes of variability, we have also identified other apparent cyclical modes around 90, 38, 24, 14-15, 911 years, as well as within the classical ENSO bandwidth (Fig. 8b). The amplitude of these modes varies through time, and future analyses must explore the driving controls upon each of these modes and their interactions before a true understanding of multi-decadal variability and regime shift events can be gained. Some of these modes could possibly be explained by known external oscillatory forcing mechanisms-e.g., at quasi-lunar ( 18 years, Royer 1993; Cook et al. 1997; Yasuda et al. 2006) and solar ( 10-12 years) time scales—but, as yet, no apparent forcing mechanism has been purported for the pentadecadal mode of variability (Minobe 2000). Synchronous decadal to multidecadal modes of variation identified in tree-ring data from the GOA and Patagonia have been attributed to large-scale coherent Pacific climate variability (Villalba et al. 2001) which may be driven by the tropics (Trenberth and Hurrell 1994; Minobe 1997; Zhang et al. 1998; Garreaud and Battisti 1999; Evans et al. 2001; Deser et al. 2004). There is also evidence of mutual modulation between North Pacific variability and ENSO at multi-decadal and higher frequencies that is not yet well understood (Allan et al. 2003; Verdon and Franks 2006). Lower frequency variations for the GOA, that can be gleaned from these ringwidth data when processed using the RCS method (D'Arrigo et al. 2006; Wiles et al. in preparation), showing cooler temperatures around the times of the Wolfe, Spörer, Maunder and Dalton solar minima (Stuiver and Braziunas 1989), may provide further support for a solar link as well as complimenting evidence from tree-ring records of glacial advance for Alaska (Wiles et al. 2004).
This study has highlighted the complex nature of the temperature variability in the GOA over the last 1,300 years. Although, in the twentieth century, GOA temperatures express a strong coherence with the PDO, it cannot be assumed that this teleconnected relationship has been stable through time or that the PDO has always been equally important as present. More comparative analysis is needed with other PDO proxies from North America and Asia (MacDonald and Case 2005; Shen et al. 2006; D'Arrigo and Wilson 2006), as well as other proxies expressing decadal oscillatory behavior in the tropics (Evans et al. 2001; D'Arrigo et al. 2005) to gain insight into the spatial coherence of these multi-decadal signals. Our analysis shows, however, that although oscillatory behavior can be identified in GOA temperatures-and therefore possibly the North Pacific as a whole-the temporal stability and the interaction of these modes of variability, as well as their causes, are not well enough understood at this time. Therefore, before improvements in forecasts of North Pacific multidecadal variability can be made, which will ultimately help future management strategies of coastal fisheries in the region of the GOA, future research must focus on understanding the processes that control regime shift changes in the region's climate. Such research will need to focus on the oscillatory modes of behavior and assess: (1) changes in their amplitude through time; (2) their mutual interaction; (3) how they interact with other large-scale synoptic phenomena such as ENSO and (4) relevant forcing mechanisms.

Acknowledgments Thank you to Ed Cook and Emma Watson for invaluable advice and comments. Figure 4 was generated using the KNMI Climate Explorer (http://www.climexp.knmi.nl). This project was funded by the National Science Foundation (Grants ATM02-02898 and OCE 04-02474). The initial manuscript was much improved from reviews from Phil Jones, Ulf Büntgen and two anonymous reviewers. Lamont-Doherty Earth Observatory Contribution No. 6973.

\section{References}

Allan R, Reason J, Lindesay J, Ansell T (2003) "Protracted" ENSO episodes and their impacts in the Indian Ocean region. Deep Sea Res 50B:2331-2347

Barclay DJ, Wiles GC, Calkin PE (1999) A 1119-year tree-ringwidth chronology from western Prince William sound, southern Alaska. Holocene 9:79-84

Beamish RJ, Benson AJ, Sweeting RM, Neville CM (2004) Regimes and the history of the major fisheries off Canada's west coast. Prog Oceanogr 60:355-385

Biondi F, Gershunov A, Cayan DR (2001) North Pacific decadal climate variability since AD 1661. J Clim 14:5-10 
Bond NA, Overland JE, Spillane M, Stabeno P (2003) Recent shifts in the state of the North Pacific. Geophys Res Lett 30(23), 2183, DOI 10.1029/2003GL018597

Box GEP, Tiao GC (1975) Intervention analysis with applications to economic and environmental problems. J Am Stat Assoc 70:70-79

Briffa KR, Jones PD, Bartholin TS, Eckstein D, Schweingruber FH, Karlen W, Zetterberg P, Eronen M (1992) Fennoscandian summers from AD 500: temperature changes on short and long timescales. Clim Dyn 7:111-119

Briffa K, Jones P, Schweingruber F, Osborn T (1998) Influence of volcanic eruptions on Northern Hemisphere summer temperature over the past 600 years. Nature 393:450-454

Büntgen U, Esper J, Frank DC, Nicolussi K, Schmidhalter M (2005) A 1052-year tree-ring proxy for alpine summer temperatures. Clim Dyn 25:141-153

Chavez FP, Ryan J, Llucha-Cota SE, Niquen M (2003) From anchovies to sardines and back: multidecadal change in the Pacific Ocean. Science 299(5604):217-221

Cook E, Briffa K, Meko D, Graybill D, Funkhouser G (1995) The 'segment length curse' in long tree-ring chronology development for palaeoclimatic studies. Holocene 5:229-237

Cook ER, Kairiukstis LA (eds) (1990) Methods of dendrochronology: applications in the environmental sciences. Kluwer Academic, Dordrecht

Cook ER, Peters K (1997) Calculating unbiased tree-ring indices for the study of climate and environmental change. Holocene 7(3):361-370

Cook ER, Meko DM, Stockton CW (1997) A new assessment of possible solar and lunar forcing of the bidecadal drought rhythm in the western US. J Clim 10:1343-1356

Cook ER, Meko DM, Stahle DW, Cleaveland MK (1999) Drought reconstructions for the continental United States. J Clim 12(4):1145-1162

Cook E, D'Arrigo R, Mann ME (2002) A well-verified, multiproxy reconstruction of the winter North Atlantic oscillation index since AD 1400. J Clim 15:1754-1764

D'Arrigo R, Wilson R (2006) On the Asian expression of the PDO. Int J Climatol 26:1607-1617. DOI 10.1002/joc.1326

D'Arrigo R, Wiles G, Jacoby G, Villalba R (1999) North Pacific sea surface temperatures: past variations inferred from tree rings. Geophys Res Lett 26:2757-2760

D'Arrigo R, Villalba R, Wiles G (2001) Tree-ring estimates of Pacific decadal climate variability. Clim Dyn 18:219-224

D'Arrigo R, Wilson R, Deser C, Wiles G, Cook E, Villalba R, Tudhope A, Cole J, Linsley B (2005) Tropical-North Pacific climate linkages over the past four centuries. J Clim 18 (24):5253-5265

D'Arrigo R, Wilson R, Jacoby G (2006) On the long-term context for late 20 th century warming. J Geophys Res 111 , D03103, DOI 10.1029/2005JD006352

Deser C, Phillips AS, Hurrell JW (2004) Pacific interdecadal climate variability: linkages between the Tropics and North Pacific during boreal winter since 1900. J Clim 17:3109-3124

Ebbesmeyer CC, Cayan DR, McLain DR, Nichols FH, Peterson DH, Redmond KT (1991) 1976 step in the Pacific climate: forty environmental changes between 1968-1975 and 19771984. In: Betancourt JL, Sharp VL (eds) Proceedings of the Seventh Annual Pacific Climate (PACLIM) Workshop, April 1990. California Department of Water Resources. Interagency ecological studies program technical report 26, $115-126$

Esper J, Cook ER, Krusic PJ, Peters K, Schweingruber FH (2003) Tests of the RCS method for reserving low-frequency variability in long tree-ring chronologies. Tree-Ring Res 59:81-98
Evans MN, Cane MA, Schrag DP, Kaplan A, Linsley BK, Villalba R, Wellington GM (2001) Support for tropicallydriven Pacific decadal variability based on paleoproxy evidence. Geophys Res Lett 28:3689-3692

Finney B, Gregory-Eaves I, Douglas M, Smol J (2002) Fisheries productivity in the northeastern Pacific Ocean over the past 2,200 years. Nature 416:729-733

Frank D, Esper J (2005) Temperature reconstructions and comparisons with instrumental data from a tree-ring network for the European Alps. Int J Climatol 25:1437-1454

Fritts HC (1976) Tree rings and climate. Academic, London

Garreaud R, Battisti D (1999) Interannual (ENSO) and interdecadal (ENSO-like) variability in the Southern Hemisphere tropospheric circulation. J Clim 12:2113-2122

Gedalof Z, Smith DJ (2001) Interdecadal climate variability and regime scale shifts in Pacific North America. Geophys Res Lett 28:1515-1518

Gedalof Z, Mantua NJ, Peterson DL (2002) A multi-century perspective of variability in the Pacific Decadal oscillation: new insights from tree rings and coral. Geophys Res Lett 29: DOI 10.1029/2002GL015824

Grissino-Mayer HD, Holmes RL, Fritts HC (1997) The International Tree-Ring Data Bank Program Library, version 2.1, Users Manual, Tucson, Arizona

Hu FS, Ito E, Brown T, Curry B, Engstrom D (2001) Pronounced climatic variations in Alaska during the last two millennia. Proc Natl Acad Sci 98:10552-10556

Hughes MK, Schweingruber FH, Cartwright D, Kelly PM (1984) July-August temperature at Edinburgh between 1721 and 1975 from tree-ring density and width data. Nature 308:341344

Jones PD, Hulme M (1996) Calculating regional climatic time series for temperature and precipitation: methods and illustrations. Int J Climatol 16:361-377

Jones PD, New M, Parker DE, Martin S, Rigor IG (1999) Surface air temperature and its variations over the last 150 years. Rev Geophys 37:173-199

Labeyrie L, Cole J, Alverson K, Stocker T (2003) The history of climate dynamics. Chapter 3. Paleoclimate, Global change and the future. Alverson K, Bradley R, Pederson T (eds) Springer, Berlin Heidelberg New York, pp 221

Linsley BK, Wellington GM, Schrag DP (2000) Decadal sea surface temperature variability in the sub-tropical South Pacific from 1726 to 1997 AD . Science 290:1145-1148

MacDonald GM, Case RA (2005) Variations in the Pacific Oscillation over the past millennium. Geophys Res Lett 32, L08703, DOI 10.1029/2005GL022478

Mann ME, Lees J (1996) Robust estimation of background noise and signal detection in climatic time series. Clim Change 33:409-45

Mantua N, Hare S (2002) The Pacific decadal oscillation. J Oceanogr 58:35-44

Mantua N, Hare S, Zhang Y, Wallace J, Francis R (1997) A Pacific interdecadal oscillation with impacts on salmon production. Bull Am Met Soc 58:1069-1079

Meko DM (1997) Dendroclimatic reconstruction with time varying subsets of tree indices. J Clim 10:687-696

Minobe S (1997) A 50-70 year climatic oscillation over the North Pacific and North America. Geophys Res Lett 24:683-686

Minobe S (1999) Resonance in bidecadal and pentadecadal climate oscillations over the North Pacific: role in climatic regime shifts. Geophys Res Lett 26:855-858

Minobe S (2000) Spatio-temporal structure of the pentadecadal variability over the North Pacific. Prog Oceanogr 47:381408 
Mitchell VL (1967) An investigation of certain aspects of tree growth rates in relation to climate in the central Canadian boreal forest. Technical report no. 33. University of Wisconsin, Department of Meteorology, Wisconsin, pp 62

Nakamura H, Lin G, Yamagata T (1997) Decadal climate variability in the North Pacific during the recent decades. Bull Am Met Soc 78:2215-2225

Osborn TJ, Briffa KB, Jones PD (1997) Adjusting variance for sample size in tree-ring chronologies and other regional mean timeseries. Dendrochronologia 15:89-99

Peterson TC, Vose RS (1997) An overview of the Global Historical Climatology Network temperature data base. Bull Am Met Soc 78:2837-2849

Rayner NA, Parker DE, Horton EB, Folland CK, Alexander LV, Rowell DP, Kent EC, Kaplan A (2003) Globally complete analyses of sea surface temperature, sea ice and night marine air temperature, 1871-2000. J Geophys Res 108, 4407, DOI 10.1029/2002JD002670

Rodionov SN (2004) A sequential algorithm for testing climate regime shifts. Geophys Res Lett 31, DOI 10.1029/ 2004GL019448

Royer TC (1993) High latitude oceanic variability associated with the 18.6 year nodal tide. J Geophys Res 98:4639-4644

Richman MB (1986) Rotation of principal components. J Clim 6:293-335

Shen C, Wang WC, Gong W, Hao Z (2006) A Pacific decadal oscillation record since $1470 \mathrm{AD}$ reconstructed from proxy data of summer rainfall over eastern China. Geophys Res Lett 33:L03702, DOI 10.1029/2005GLO24804

Stuiver M, Braziunas TF (1989) Atmospheric C-14 and centuryscale solar oscillations. Nature 338:405-408

Trenberth K, Hurrell J (1994) Decadal atmospheric-ocean variations in the Pacific. Clim Dyn 9:303-319

Vautard R, Ghil M (1989) Singular spectrum analysis in nonlinear dynamics with applications to paleoclimatic time series. Physica D 35:395-424

Verdon DC, Franks SW (2006) Long-term behaviour of ENSO: Interactions with the PDO over the past 400 years inferred from paleoclimate records. Geophys Res Lett 33:L06712, DOI 10.1029/2005GL025052

Villalba R, D'Arrigo R, Cook ER, Jacoby GC, Wiles GC (2001) Decadal-scale climatic variability along the extratropical western coast of the Americas: evidence from tree-ring records. In: Markgraf $\mathrm{V}$ (ed) Interhemispheric climate linkages. Academic, New York, pp 155-172

Wigley TML, Briffa KR, Jones PD (1984) On the average of correlated time series, with applications in dendroclimatology and hydrometeorology. J Clim App Met 23:201-213

Wiles G, D'Arrigo R, Jacoby G (1998) Gulf of Alaska atmosphere-ocean variability over recent centuries inferred from coastal tree-ring records. Clim Change 38:289-306

Wiles G, D'Arrigo R, Villalba R, Calkin P, Barclay D (2004) Century-scale solar variability and Alaskan temperature change over the past millennium. Geophys Res Lett 31:L15203, DOI 10.1029/2004GL020050

Wiles G, Brady K, D'Arrigo R, Calkin P, Wilson R (in preparation). A 1300 year-long tree-ring record from Columbia Bay, Southern Alaska

Wilson JG, Overland JE (1987) Meteorology. In: Hood DW, Zimmerman ST (eds) The Gulf of Alaska: physical environment and biological resources. Nat Ocean Atmos Adm US Department of Commerce, pp 31-56

Wilson RJS, Luckman BH, Esper J (2005) A 500-year dendroclimatic reconstruction of spring/summer precipitation from the lower Bavarian Forest region, Germany. Int J Climatol 25:611-630

Yasuda I, Osafune S, Tatebe H (2006) Possible explanation linking 18.6-year period nodal tidal cycle with bi-decadal variations of ocean and climate in the North Pacific. Geophys Res Lett 33, L08606, DOI 10.1029/2005GL025237

Zhang Y, Norris J, Wallace J (1998) Seasonality of large-scale atmosphere-ocean interaction over the North Pacific. J Clim $11: 2473-2481$ 